\title{
LÍNGUA, PATERNALISMO E AUTORITARISMO EM DINOSSAURO EXCELENTÍSSIMO, DE JOSÉ CARDOSO PIRES
}

Cíntia França Ribeiro - FALE/UFMG

O slogan do governo ditatorial português de Salazar, "Deus, Pátria e Família”, poderia muito bem ser subsumido à palavra latina pater, relacionada ao campo semântico dos três elementos do lema. Deus, na tradição judaico-cristã dominante na Europa ocidental, é comumente designado, numa perspectiva marcadamente sexista que não está em discussão aqui, como o Pai Supremo. Quanto à família, o vínculo é igualmente claro, uma vez que o pai é um membro da família e, mais importante, num modelo familiar patriarcal grandemente influenciado e determinado pela mesma tradição judaico-cristã que representa Deus como uma figura masculina, ele é o chefe da família. A palavra portuguesa pátria, por sua vez, apesar da obviedade de ter sua origem histórica na palavra latina pater, pode levantar um ponto mais interessante a ser considerado.

Em português, como provavelmente na maioria das línguas, há uma série de opções para realizar o significado de pátria: nação, país, terra natal, por exemplo. A preferência específica por uma alternativa e não por outras não é casual, nem inconsequente. No caso do slogan salazarista, a consequência da escolha de pátria em detrimento de seus sinônimos aproximados ${ }^{1}$ é exatamente a grande unidade harmônica de sentido entre as três palavras, que podem, de alguma forma, remontar ao denominador comum pater. Os três valores são apresentados como intrinsecamente conectados, e a contiguidade entre eles confere à Pátria o sentido de uma unidade natural indissolúvel que está acima do indivíduo, à qual, por um

1"Sinônimos aproximados" deveria, é claro, ser considerada uma expressão redundante, uma vez que duas palavras não podem ter ou sugerir exatamente os mesmos significados. Caso contrário, a própria afirmação de que a escolha de uma em detrimento de outra não é inconsequente seria um contra-senso. Entretanto, dado o profundo enraizamento da ideia de sinonímia no senso comum, é prudente explicitar tanto quanto possível. 
lado, ele deve lealdade, respeito e obediência, e, da qual, por outro lado, ele espera receber proteção e garantia de subsistência. Em outras palavras, a Pátria é uma fonte de incontestável autoridade e também provedora, como um pai, e a língua, como se pode inferir dessa simples análise do slogan de Salazar, desempenhou um papel incrivelmente importante na construção dessa imagem para o governo ditatorial português de 1926 a 1974 e na moldagem de comportamentos congruentes com esse governo. Tal uso da língua não passou despercebido pelos escritores portugueses da época ${ }^{2}$, e Dinossauro Excelentíssimo, de José Cardoso Pires, é, como será examinado nesse estudo, um exemplo notável de trabalho literário que encena, através da representação satírica do regime salazarista, a complexa relação entre a língua e a constituição do Estado autoritário e paternalista em que consistiu o Estado Novo português, sintetizado em "Deus, Pátria e Família”.

Apresentado como uma fábula contada por um pai a uma filha, Dinossauro Excelentíssimo é a história de um ditador, o dinossauro do título, de sua infância à sua morte. Nascido de um casal de pobres camponeses no Reino de Mexilhões, ele demonstra um incomum talento para lidar com palavras desde uma idade muito precoce, e todas as pessoas que lhe punham os olhos em cima previam para ele um futuro brilhante, quer como advogado, quer como membro da Igreja ou do exército. Esse talento se torna uma obsessão à medida que o ditator cresce e vai estudar na Cidade dos Doutores, para onde é levado ainda muito jovem pelos pais no lombo de uma mula, num episódio que lembra a fuga de José e Maria para dar à luz o menino Jesus. Como o narrador adverte na introdução da história, o dinossauro era "um imperador que na ânsia de purificar as palavras acabou por ficar entrevado com a paralisia da mentira." (PIRES, 1999, p. 13) Dessa forma, em princípio o imperador é devotado a uma aparentemente nobre tarefa que resulta, entretanto, numa realização abominável.

\footnotetext{
2 Nem todos os escritores, é claro, usaram a literatura para se opor explicitamente ao regime. Não me refiro aqui exatamente ao uso político deliberado da literatura, mas à consciência, percebida através do texto, quer o escritor pessoalmente a manifeste ou não (essa manifestação pessoal pode ser, de fato, irrelevante), de que a língua necessariamente constrói imagens que medeiam, e portanto condicionam, nossa percepção da realidade e nossa relação com ela. Um escritor que ignora essa característica da língua talvez sequer devesse ser chamado propriamente de escritor.
} 
É relevante que o primeiro ponto destacado pelo narrador seja o modo como o personagem principal, sendo um ditador, lida com a língua, porque a língua, e as representações construídas com ela, são uma questão política das mais importantes, e os regimes autoritários normalmente a administram por meio da censura e da propaganda. Ambos os instrumentos têm a finalidade de impor e preservar a autoridade do Estado às custas da liberdade individual. A proibição de discurso materializada na censura e a manifestação obrigatória da ideologia oficial são, pois, meios complementares: o primeiro impede ideias divergentes de surgirem e se espalharem, enquanto o segundo produz um discurso unívoco de legitimação. Os dois recursos estão em operação no fictício Reino de Mexilhões sob domínio do imperador Dinossauro.

Em Dinossauro Excelentíssimo, como no mundo real, a censura é associada à tortura. O corpo a ser torturado, entretanto, não é o humano, mas o das próprias palavras. Elas deveriam pertencer a uma linhagem nobre, tradicional e identificável a fim de entrar no léxico, e a Câmara de Torturar Palavras era o instrumento inventado pelo Dinossauro para purificar suas vítimas. Através do processo de tortura, pretendia-se que a língua fosse destituída de palavras perigosas e perniciosas que "pingavam de certeza veneno nas entrelinhas." (PIRES, 1999, p. 51) Nessa busca pelo veneno das palavras, a censura produzia insegurança e medo por meio de seus procedimentos assistemáticos, uma vez que jornalistas, escritores, políticos e agentes da mídia em geral nunca sabiam se seus textos atravessariam incólumes o controle do censor. A ameaça de censura e tortura - e ambas coincidem em Dinossauro Excelentíssimo - tem ainda outro efeito, não menos importante: a unificação do discurso. Como explica Cardoso Pires no ensaio "Técnica do golpe de censura", a censura oficial gerou várias censuras paralelas, ou autocensuras:

Mas fora da cumplicidade jurídico-policial e das suas ramificações militares que garantem a Censura do Estado, geram-se espontaneamente na sociedade fechada outras zonas de vigilância que resultam do clima de medo e de corrupção em vigor. (PIRES, 1977, p. 220-221) 
A censura implicou, assim, por parte dos cidadãos e da mídia, não apenas a abstenção de disseminar determinadas ideias, mas também o dever de repetir determinada ideologia. A reprodução do discurso oficial não era simplesmente uma questão de convicção ideológica. Significava, frequentemente, mero oportunismo, como Pires argumenta no mesmo ensaio (PIRES, 1977, p. 220-223), o qual funciona, nesse ponto, como uma explicitação das representações satíricas de seu trabalho ficcional, em que o ditador é cercado pelos “doutores”, ou DRs - a corrupta elite burocrática que tira proveito de sua função pública para obter privilégios pessoais que aprendem e repetem as palavras de Dinossauro:

\footnotetext{
Os conselheiros e bacharéis que se prezavam iam moldando a voz sem mesmo se aperceberem, muitos deles. [...] Ao longo dos dias a escalada para a música imperial, a marcha para a voz, para o tom, carregava-se de dificuldades. Os notáveis não esmoreciam. Continuavam a afiar o casco da unha nos dicionários, esmagando os termos que o Imperador ia abatendo no gabinete. $O$ terreno aclarava-se. Vinha mais adiante a frase: venciam-na, davam-lhe a volta precisa, a tal. [...] Finalmente, quando se consideravam afinados, desataram a discursar à rédea solta, atravessando os ecrãs da televisão, praças públicas e por cima de toda a folha de jornal.

E o Mestre? O Mestre, lendo-os ou ouvindo-os albardados com as frases imperiais, fazia de conta que não percebia que se estava a ouvir. (PIRES, 1999, p. 74-75)
}

A língua é, dessa forma, um meio de manter o statu quo que favorecia a elite burocrática, alimentando um Estado cujo único propósito de existência era a preservação de seu próprio poder e autoridade.

A imposição de manifestar um certo discurso é uma implicação que a censura tem em comum com a propaganda: ambas são práticas produtoras de discurso e, no caso específico da propaganda fascista de Salazar/Dinossauro, a semelhança vai ainda mais longe, já que os discursos resultantes são impostos pela autoridade e força do Estado. Pode-se dizer, com Barthes, que o discurso do fascismo ecoa o fascismo da própria língua:

Mas a língua, como desempenho de toda linguagem, não é nem reacionária, nem progressista; ela é simplesmente: fascista; pois o fascismo não é impedir de dizer, é obrigar a dizer. (BARTHES, 2007, p. 14) 
E a imagem de Dinossauro disseminada pelos meios de comunicação, discursos e iconografia dizia que o imperador era um homem sábio, sério e severo, um guardião da tradição e dos valores morais, a perfeita figura do velho pai que protege a família - uma metáfora do país nos discursos paternalistas - da dissolução, representada, em Dinossauro Excelentíssimo, pelos rebeldes Pedintes Voadores. O discurso de Dinossauro era de conformismo a um suposto destino, como se a realidade dos fatos, isto é, a pobreza de seu reino, fosse resultado de uma vontade maior à qual os homens deveriam se resignar:

Começou por citar a conhecida história da "Camisa do Homem Feliz" que é aquela que descreve a alegria de ser-se pobre e a difícil e infeliz vida dos ricos. [...] Para terminar, levantou os braços à divina Providência: "DEUS CONCEDEU-NOS A GRAÇA DE NOS QUERER POBRES.” (PIRES, 1999, p. 4849)

A associação dos discursos político e religioso é um ponto importante na legitimação do regime ditatorial português, porque provê a ditadura de uma importantíssima fonte de legitimidade. Em Portugal, da mesma forma que em seu espelho ficcional, essa estratégia foi extremamente poderosa, dada sua forte tradição católica. O Estado resultante dessa associação tinha, assim, sua autoridade legitimada, e sua ideologia apresentada como a única verdadeira. Toda a estrutura social era naturalizada e dotada dos atributos de perfeição e eternidade, já que era resultado do plano divino. Qualquer mudança, se houvesse alguma, deveria vir de cima, dos governantes cuja autoridade foi dada pela vontade de Deus. Legitimada dessa maneira, a autoridade do Estado não poderia ser objeto de nenhuma prestação de contas:

[...] ao se manter atrelado à concepção católica, o Estado português tem sido baseado historicamente na reciprocidade de um sistema patronalclientelista - um Estado que era natural, moral e justo, e portanto não precisava ser limitado por um sistema institucional de freios e contrapesos. (WIARDA, 1979, p. 93, minha tradução)

3 Originalmente, em inglês: "[...] in keeping with the Catholic conception, the Portuguese state has historically been based on the reciprocity of a patron-client system - a state that was natural, moral, and just and therefore did not have to be limited by institutional checks and balances." (WIARDA, 1979, p. 93) 
O Estado naturalizado era, portanto, por um lado, autorizado a se impor sobre os indivíduos e opositores por qualquer meio, incluindo a tortura e a censura quando supostamente necessário. Por outro lado, a naturalização da hierarquia estatal, associada a um pesado corpo burocrático e realizada por ele, moldou a relação de dependência entre cidadãos e Estado que caracteriza o Estado paternalista, no qual os cidadãos não são estimulados a participar do governo e a transformá-lo em autogoverno, uma vez que o poder não emana do povo.

O Estado Novo encorajou ativamente a apatia política por parte dos indivíduos e proibiu a formação de grupos políticos. Havia pouca informação sobre os líderes políticos e suas ações disponível para o público. Enquanto o índice oficial de alfabetização era de cerca de $70 \%$, a alfabetização efetiva em áreas rurais era muito menor. Todos os meios de comunicação de massa estavam sob controle governamental e eram censurados. Em vez de participar da política local ou direcionada a níveis superiores, os camponeses portugueses sofriam, constante e abusivamente, a imposição de uma série de medidas administrativas. (RIEGELHAUPT, 1979, p. 182, minha tradução) ${ }^{4}$

Tudo que foi dito sobre Portugal se aplica ao Reino de Mexilhões:

Dito e feito. Mãos ao trabalho, e ei-lo [o imperador] a limpar decretos e alíneas, jornais, compêndios - o que calhava. (PIRES, 1999, p. 51)

Seria o cúmulo da estupidez pensar que o Mestre se deixava iludir com os analfabetos em trânsito, acreditando que eles estavam de boca aberta para lhes beber as palavras (PIRES, 1999, p. 83)

Em Dinossauro Excelentíssimo, o discurso oficial projeta um Estado autoritário e paternalista legítimo cujo principal instrumento para dominar e alienar o povo é o controle da língua, quer este controle implique a proibição de dizer, quer implique a obrigação de dizer. Em qualquer caso, a preocupação demonstrada por regimes políticos ${ }^{5}$ com as performances da língua deve lembrar quão poderosas são

\footnotetext{
4 No original em inglês: "The Estado Novo actively encouraged political apathy on the parts of individuals and prohibited the formation of political groups. Little information was avaiable to the public about political leaders and their doings. While the official literacy rate was about 70 percent, the effective literacy rate in rural areas was much lower. All mass media were under government control and censored. Instead of participating in local or upwardly directed politics, the Portuguese villagers were constantly being presented with and harassed by a series of administrative decisions." (RIEGELHAUPT, 1979, p. 182)

$5 \mathrm{E}$ isso se aplica também a regimes democráticos, já que a preocupação com a liberdade de
} 
as representações veiculadas por ela na construção da realidade, e talvez a ficção literária seja o meio mais adequado de lembrar isso, porque é, como a realidade, feita também de palavras.

\section{REFERÊNCIAS}

BARTHES, Roland. Aula. Trad. Leyla Perrone-Moisés. 13 ed. São Paulo: Cultrix, 2007.

PIRES, José Cardoso. Dinossauro Excelentíssimo. 7 ed. Lisboa: Dom Quixote, 1999.

PIRES, José Cardoso. Técnica do golpe de censura. In: . E agora, José?. 1 ed. Lisboa: Moraes, 1977. P. 198-243.

RIEGELHAUPT, Joyce Firstenberg. Peasants and politics in Salazar's Portugal: the corporate state and village "nonpolitics". In: Contemporary Portugal. Edited by Lawrence S. Graham and Harry M. Makler. Austin and London: University of Texas Press, 1979. P. 167-190.

WIARDA, Howard J. The corporatist tradition and the corporative system in Portugal: structured, evolving, transcended, persistent. In: Contemporary Portugal. Edited by Lawrence S. Graham and Harry M. Makler. Austin and London: University of Texas Press, 1979. P. 89-122. 